\title{
Hubungan Kecepatan Pendinginan Air dengan Kecepatan Tiupan Udara
}

\author{
Taat Guswantoro"), Manogari Sianturi, Nurafni Prapitasari, Areli Elona \\ Program Studi Pendidikan Fisika, FKIP, Universitas Kristen Indonesia. Jl. Mayjen. Sutoyo No. 2, \\ Cawang, Jakarta Timur. \\ E-mail: taat_toro@yahoo.co.id \\ Hp: 085712905199
}

\begin{abstract}
In this study hot water was placed in two erlenmeyer scale $100 \mathrm{ml}$ clogged and without plug, each filled with $150 \mathrm{ml}$ hot water and allowed to cool in air. Measurement of water temperature using sensor connected to the interface and recorded using the pasco capstone 14.1. The wind is raised with the fan, to adjust the wind speed by adjusting the fan distance, the speed is measured using an anemometer. The water cooling constant is obtained by a decay exponential regression analysis of temperature vs time. The relationship between water colling coefficient with wind speed is used linear regression. From the research, the water cooling coefficient naturally for clogging erlenmeyer is $3,1 x$ $10^{-4} \mathrm{~s}^{-1}$ and for erlenmeyer without plug $3.8 \times 10^{-4} \mathrm{~s}^{-1}$, the rate of change of water cooling constant to wind speed is $1,4 \times 10^{-4} \mathrm{~m}^{-1}$.
\end{abstract}

Keywords: Water cooling, heat transfer, convection

\begin{abstract}
Abstrak: Pada penelitian ini air panas ditempatkan dalam dua buah erlenmeyer berskala $100 \mathrm{ml}$ bersumbat dan tanpa sumbat, masing-masing diisi air panas dengan volume $150 \mathrm{ml}$ dan dibiarkan mendingin di udara. Pengukuran suhu air dengan menggunakan sensor panas yang dihubungkan ke interface dan dicatat menggunakan program pasco capstone 14.1. Angin dibangkitkan dengan kipas, untuk mengatur kecepatan angin dengan cara mengatur jarak kipas, kecepatan angin diukur menggunakan anemometer. Konstanta pendinginan air diperoleh dengan analisis regresi eksponensial meluruh dari data suhu dan waktu. Hubungan antara koefisien pendinginan air dengan kecepatan angin digunakan regresi linier. Dari penelitian diperoleh koefisien pendinginan air secara alami untuk erlenmeyer tersumbat sebesar 3,1 $\times 10^{-4} \mathrm{~s}^{-1}$ dan untuk erlenmeyer tanpa sumbat sebesar $3,8 \times 10^{-4} \mathrm{~s}^{-1}$, laju perubahan konstanta pendinginan air terhadap kecepatan angin adalah sebesar $1,4 \times 10^{-4} \mathrm{~m}^{-1}$.
\end{abstract}

Kata Kunci : Pendinginan air, transfer panas, konveksi

\section{PENDAHULUAN}

Benda bersuhu tinggi ketika berada di udara bebas akan kehilangan energi panas karena energi panasnya ditransfer oleh partikel-partikel udara disekitar benda tersebut secara konveksi. Transfer panas secara konveksi dapat terjadi secara baik alami maupun secara paksaan yaitu dengan mengalirkan fluida pada benda panas agar fluida tersebut mengambil panas dari benda. Koefisien konveksi paksa suatu fluida akan meningkat ketika fluida tersebut diberikan suspensi partikel padat berukuran nano. Fluida air bersuspensi partikel nano $\mathrm{Al}_{2} \mathrm{O}_{3}$ dan mendapatkan peningkatan koefisien konveksi paksa lebih dari 31\% (Putra, 2005).

Proses transfer panas secara konveksi menyebabkan benda panas akan menjadi dingin. Sebuah sistem pendingin dengan memanfaatkan konveksi alami akan lebih efektif ketika menggunakan penukar panas berupa pipa dan kawat, seperti penukar panas pada lemari pendingin. Efisiensi dari penukar panas yang memanfaatkan konveksi bergantung pada geometri penukar panas, Ma'sum pada tahun 2012 berhasil meningkatkan efisiensi penukar panas sebesar 4\% dengan massa penukar panas berkurang 19\% (Ma'sum, 2012). 
Hukum Newton tentang pendinginan menyebutkan bahwa laju pendinginan berbanding lurus dengan selisih suhu benda dengan suhu ruangan. Penurunan suhu pada pendinginan mengikuti kurva peluruhan, dengan mengetahui konstanta waktu peluruhan maka dapat ditentukan koefisien konveksi suatu fluida. Penggunaan perangkat lunak akan memudahkan dalam perhitungan koefisien konveksi ini, Ramadhanti menggunakan Coachlab II + untuk menentukan koefisien konveksi bahan-bahan tertentu (Ramadhanti, 2014).

Meniupkan udara ke benda panas dapat mempercepat proses pendinginan benda tersebut, seperti saat sedang menikmati secangkir kopi, agar lebih cepat dingin maka seseorang akan meniup kopi tersebut. Dalam penelitian ini peneliti menentukan hubungan kecepatan pendinginan air dengan kecepatan tiupan udara dengan perangkat lunak Pasco Capstone 14.1 dan Originpro 8.0.

\section{TEORI}

Hukum Newton tentang pendinginan air menyatakan bahwa laju penurunan suhu berbanding lurus dengan selisih suhu air dan ruangan, secara matematis dirumuskan sebagai:

$$
\frac{d T}{d t}=-\alpha\left(T-T_{0}\right)
$$

dengan $\alpha$ adalah konstanta pendinginan air $\quad\left(\mathrm{s}^{-1}\right), T$ adalah suhu air $\left({ }^{\circ} \mathrm{C}\right)$ dan $T_{0}$ adalah suhu ruangan $\left({ }^{\circ} \mathrm{C}\right)$. Penurunan persamaan $(1)$ akan menghasilkan persamaan:

$$
T(t)=T_{0}+\left(T_{1}-T_{0}\right) e^{-\alpha t}
$$

Dengan $T_{l}$ adalah suhu awal air panas $\left({ }^{\circ} \mathrm{C}\right)$.

\section{METODE PENELITIAN}

Penelitian ini dilakukan di laboratorium Fisika Dasar, Universitas Kristen Indonesia. Metode pengambilan data adalah sebagai berikut:

1) Menghubungkan 8 sensor suhu ke Interface pasco.

2) Menghubungkan interface pasco ke PC.

3) Mengaktifkan program pasco capstone 14.1.

4) Mensetel untuk pencatatan suhu setiap 1 menit.

5) Mempersiapkan 2 buah erlenmeyer dengan skala $100 \mathrm{ml}$.

6) Mengisi masing-masing erlenmeyer dengan air panas masing-masing $150 \mathrm{ml}$.

7) Memasangkan sensor suhu $T_{1}$ pada erlenmeyer dengan sumbat, dan $T_{2}$ pada erlenmeyer tanpa sumbat.

8) Menekan tombol start pada program.

9) Mengamati penurunan suhu air selama 2 jam.

10) Mengulangi dengan memberikan angin dari kipas angin.

11) Menyalin data suhu ke dalam microsoft excel.

Metode pengolahan data sebagai berikut:

1) Mengatifkan program origin 8.0.

2) Menyalin data dari microsoft excel ke Origin 8.0.

3) Plot grafik dengan sumbu $x$ adalah waktu dan sumbu $y$ adalah suhu. Pilih analisis regresi peluruhan eksponensial untuk memperoleh konstanta pendinginan air $(\alpha)$.

4) Plot grafik dengan sumbu $x$ adalah koefisien pendinginan air pada erlenmeyer dengan sumbat dan sumbu $y$ koefisien pendinginan air pada erlenmeyer tanpa sumbat. Pilih analisis regresi linier.

5) Plot grafik dengan sumbu $x$ adalah kecepatan angin dan sumbu $y$ koefisien pendinginan air pada erlenmeyer dengan sumbat. Pilih analisis regresi linier. 
6) Plot grafik dengan sumbu $x$ adalah kecepatan angin dan sumbu $y$ koefisien pendinginan air pada erlenmeyer tanpa sumbat. Pilih analisis regresi linier.

\section{HASIL DAN PEMBAHASAN}

\subsection{Suhu Sebagai Fungsi Waktu}

Air panas pada penelitian ini ditempatkan pada erlenmeyer yang terbuat dari kaca bening, sehingga perpindahan kalor dari air ke udara dapat melalui radiasi, konduksi dan konveksi. Pada penelitian ini digunakan sensor suhu dengan ketelitian hingga $0,01{ }^{\mathrm{O}} \mathrm{C}$, sehingga penurunan suhu yang kecil dapat terekam dengan baik. Angin untuk meniup gelas dibangkitkan dengan kipas angin dengan 3 kecepatan, untuk mendapatkan variasi kecepatan angin yang lebih banyak dilakukan dengan mengubah jarak kipas angin terhadap erlenmeyer. Pengukuran kecepatan angin digunakan anemometer digital, selain dapat mengukur kecepatan angin, pada anemometer juga dapat mengukur suhu angin.

Gambar 1 merupakan grafik hubungan antara suhu air terhadap waktu dari erlenmeyer yang diberi sumbat, sedangkan gambar 2 adalah untuk erlenmeyer terbuka. Dari gambar 1 dan gambar 2 dapat dilihat bahwa penurunan suhu mengikuti grafik peluruhan, hal ini sesuai dengan teori yang dikemukakan oleh Newton bahwa kecepatan penurunan suhu air sebanding dengan perbedaan suhu ar dengan lingkungan. Air panas pada saat mula-mula suhunya akan menurun dengan cepat semakin lama suhunya akan turun dengan lambat dan pada akhirnya akan sama dengan suhu lingkungan. Pada saat masih panas perbedaan suhu antara air dan lingkungan cukup besar sehingga suhu air akan menurun lebih cepat. Penurunan suhu air yang mengikuti peluruhan ini sesuai dengan persamaan (2).

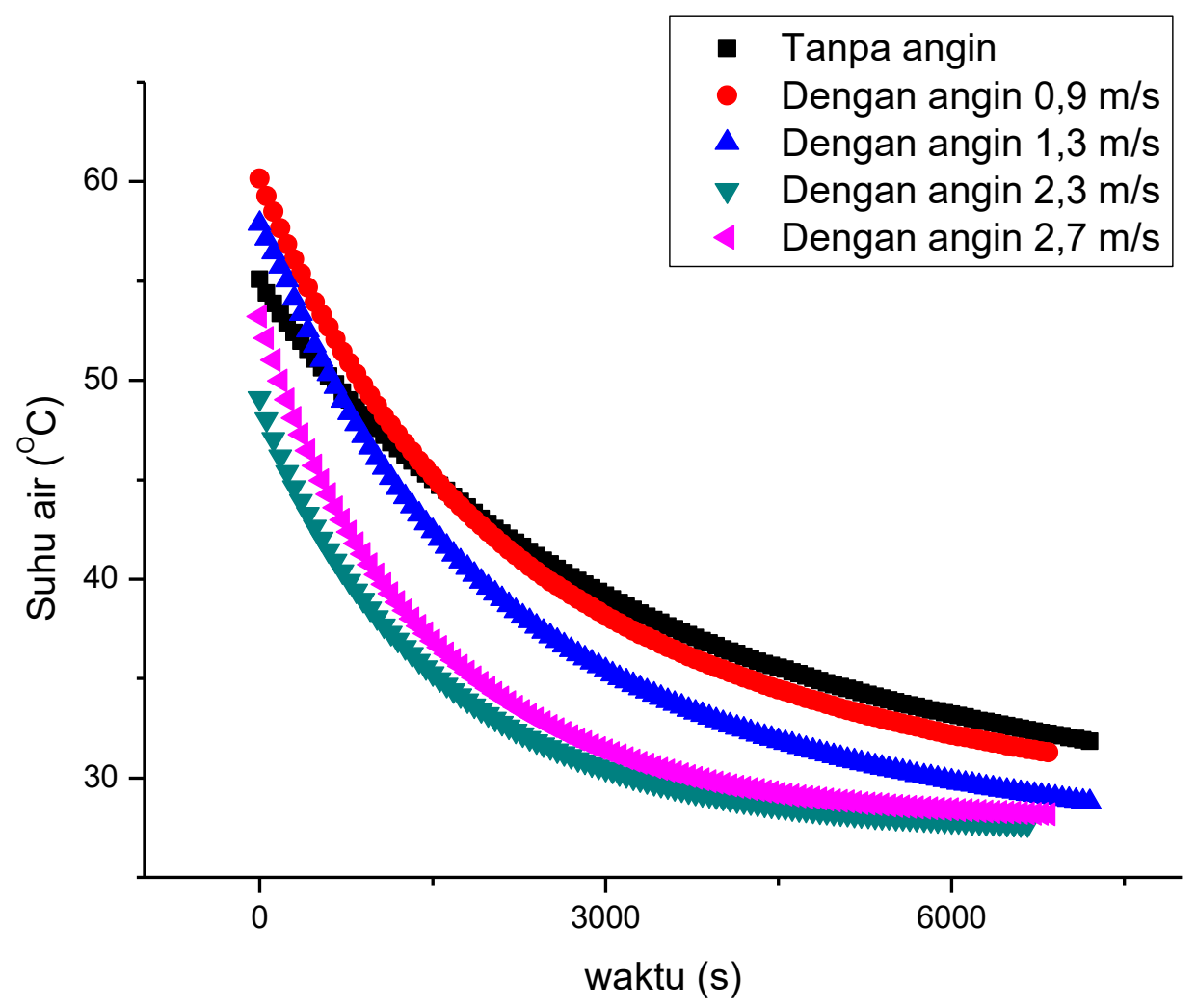

Gambar 1. Grafik hubungan suhu air terhadap waktu pada erlenmeyer dengan sumbat. 


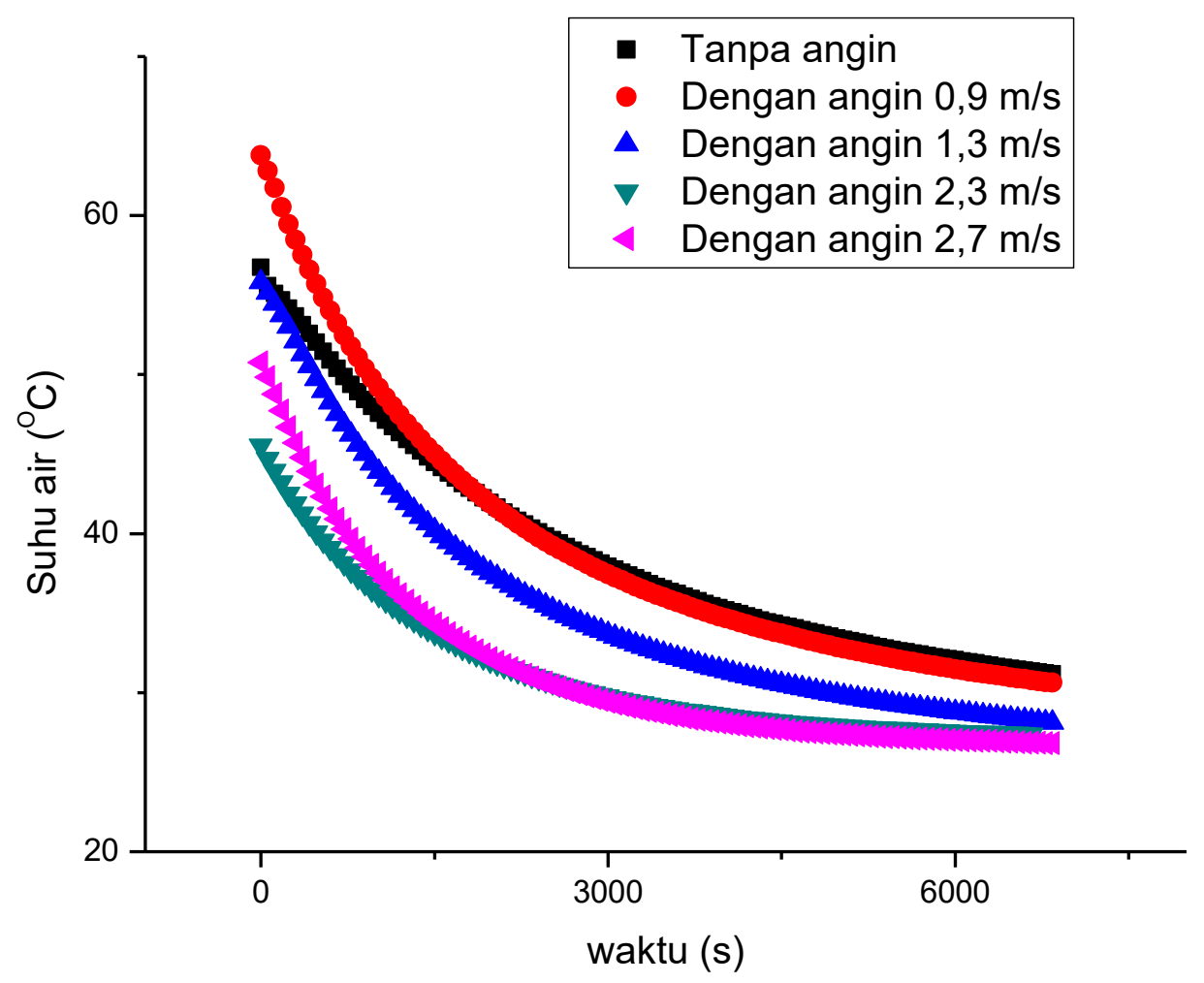

Gambar 2. Grafik hubungan suhu air terhadap waktu pada erlenmeyer tanpa sumbat.

Analisis regresi grafik peluruhan pada program originpro 8.0 menghasilkan persamaan:

$$
T=T_{0}+\left(T_{1}-T_{0}\right) e^{-t / \tau}
$$

dengan $\tau$ adalah waktu karakteristik pendinginan air. Dengan demikian nilai konstanta pendinginan air dapat dicari dengan persamaan:

$$
\alpha=\tau^{-1}
$$

\subsection{Perhitungan Koefisien Pendinginan Air}

Waktu karakteristik memiliki arti fisis seberapa lama panas dapat bertahan pada air, sehingga semakin lama waktu karakteristik maka akan semakin lama air akan mendingin. Perhitungan waktu karakteristik dengan memanfaatkan regresi eksponensial dari data pada gambar 1 dan 2, regresi eksponensial yang digunakan adalah jenis peluruhan sesuai dengan persamaan (3), dan diperoleh konstanta seperti pada tabel 1 dan tabel 2.

Pada tabel 1 dan tabel 2 juga disajikan nilai konstanta pendinginan air yang diperoleh dari persamaan (4). Konstanta pendinginan air menunjukkan kecepatan air mendingin, sehingga semakin besar konstanta pendinginan maka akan lebih cepat pula penurunan suhu air. 
Tabel 1. Koefisien persamaan suhu sebagai fungsi waktu pada erlenmeyer dengan sumbat berdasarkan persamaan (4) dan (5) untuk berbagai kecepatan angin.

\begin{tabular}{ccccc}
\hline $\boldsymbol{v}(\mathbf{m} / \mathbf{s})$ & $\boldsymbol{T}_{\boldsymbol{0}}\left({ }^{\mathbf{0}} \mathbf{C}\right)$ & $\boldsymbol{T}_{\boldsymbol{1}}\left({ }^{\mathbf{0}} \mathbf{C}\right)$ & $\boldsymbol{\tau}(\mathbf{s})$ & $\boldsymbol{\alpha}\left(\mathbf{s}^{\mathbf{- 1}}\right)$ \\
\hline 0,0 & 29,49 & 54,68 & 3128 & 0,00032 \\
0,9 & 30,23 & 59,62 & 2265 & 0,00044 \\
1,3 & 28,19 & 57,75 & 2102 & 0,00048 \\
2,3 & 27,48 & 48,52 & 1509 & 0,00066 \\
2,7 & 28,05 & 52,73 & 1469 & 0,00068 \\
\hline
\end{tabular}

Tabel 2. Koefisien persamaan suhu sebagai fungsi waktu pada erlenmeyer tanpa sumbat berdasarkan persamaan (4) dan (5) untuk berbagai kecepatan angin.

\begin{tabular}{ccccc}
\hline $\boldsymbol{v}(\mathbf{m} / \mathbf{s})$ & $\boldsymbol{T}_{\boldsymbol{0}}\left({ }^{\mathbf{0}} \mathbf{C}\right)$ & $\left.\boldsymbol{T}_{\boldsymbol{1}} \boldsymbol{(}^{\mathbf{0}} \mathbf{C}\right)$ & $\boldsymbol{\tau}(\mathbf{s})$ & $\boldsymbol{\alpha}\left(\mathbf{s}^{\mathbf{- 1}}\right)$ \\
\hline 0,0 & 29,42 & 56,45 & 2589 & 0,00039 \\
0,9 & 30,22 & 63,02 & 1935 & 0,00052 \\
1,3 & 27,73 & 55,90 & 1896 & 0,00053 \\
2,3 & 27,30 & 45,16 & 1482 & 0,00067 \\
2,7 & 26,87 & 50,52 & 1309 & 0,00076 \\
\hline
\end{tabular}

\subsection{Perbandingan Koefesien Pendinginan Air dengan Angin dan Tanpa Angin.}

Tabel 1 dan tabel 2 menunjukkan bahwa semakin cepat angin yang ditiupkan maka konstanta pendinginan air menjadi lebih besar, hal ini menunjukkan bahwa dengan meniupkan angin akan mempercepat laju pendinginan air. Hal ini disebabkan karena ketika semakin cepat angin ditiupkan pada air panas, akan semakin cepat pula energi panas air diambil oleh partikel-partikel udara yang menyentuh permukaan erlenmeyer. Perpindahan panas yang diakibatkan oleh tiupan angin ini adalah perpindahan panas melalui konveksi, ketika dilakukan tanpa memberikan angin maka konveksi berlangsung secara alami, sedangkan ketika dengan menambahkan angin maka konveksi yang terjadi adalah konveksi paksa. 


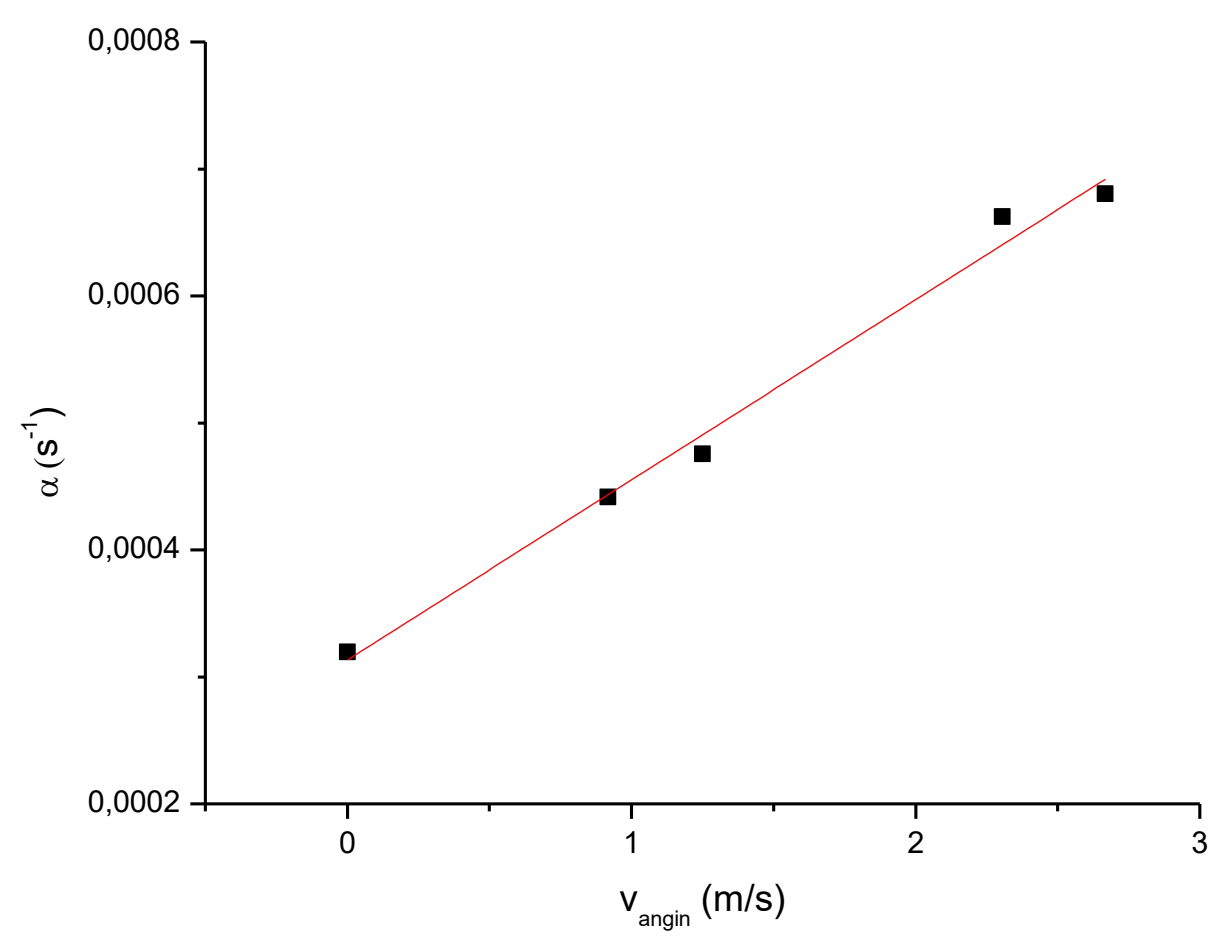

Gambar 3. Analisis regresi linier hubungan antara konstanta pendinginan air dan kecepatan angin pada erlenmeyer dengan sumbat

Menggunakan regresi linier antara kecepatan angin dan koefisien pendinginan air untuk erlenmeyer dengan sumbat seperti pada gambar 3 diperoleh persamaan :

$$
\alpha=3,1 \times 10^{-4}+1,4 \times 10^{-4} v
$$

dengan $R^{2}$ sebesar 0,9876. Intersepsi persamaan (5) menunjukkan koefisien pendinginan air tanpa kehadiran angin untuk erlenmeyer dengan sumbat sebesar $3,1 \times 10^{-4} \mathrm{~s}^{-1}$, dan slope adalah laju penambahan koefisien pendinginan air terhadap kecepatan angin yaitu sebesar $1,4 \times 10^{-4}$ $\mathrm{m}^{-1}$.

Dengan cara yang sama hubungan antara kecepatan angin dan koefisien pendinginan air untuk erlenmeyer tanpa sumbat seperti pada gambar 4 diperoleh persamaan :

$$
\alpha=3,8 \times 10^{-4}+1,4 \times 10^{-4} v
$$

dengan $R^{2}$ sebesar 0,9772 . Intersepsi persamaan (6) menunjukkan koefisien pendinginan air tanpa kehadiran angin untuk erlemeyer tanpa sumbat sebesar $3,8 \times 10^{-4} \mathrm{~s}^{-1}$, dan slope adalah laju penambahan koefisien pendinginan air terhadap kecepatan angin yaitu sebesar $1,4 \times 10^{-4}$ $\mathrm{m}^{-1}$.

Perhitungan untuk menentukan hubungan konstanta pendinginan air dan kecepatan tiupan angin menggunakan regresi linier menghasilkan laju yang sama, baik untuk erlenmeyer dengan sumbat maupun tanpa sumbat yaitu sebesar $1,4 \times 10^{-4} \mathrm{~m}^{-1}$. Secara umum dari persamaan (5) dan (6) persamaan konstanta pendinginan air sebagai fungsi kecepatan angin adalah sebagai berikut:

$$
\alpha=\alpha_{0}+1,4 \times 10^{-4} v
$$


Dengan $\alpha_{0}$ adalah besarnya konstanta pendinginan air tanpa menggunakan angin.

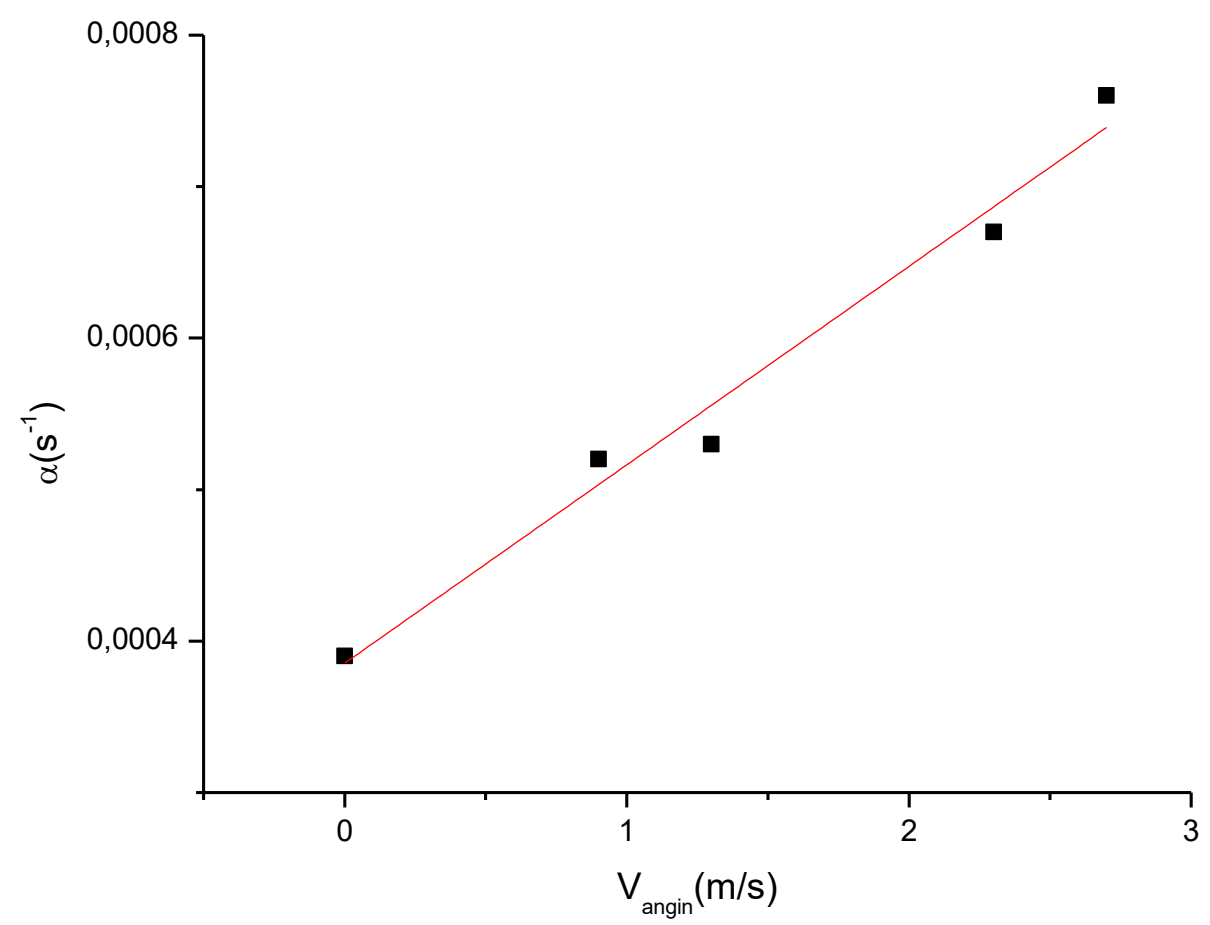

Gambar 4. Analisis regresi linier hubungan antara konstanta pendinginan air dan kecepatan angin pada erlenmeyer tanpa sumbat

\subsection{Perbandingan Koefesien Pendinginan Air dari Erlenmeyer dengan Sumbat dan Tanpa Sumbat.}

Besarnya laju pendinginan air juga bergantung dengan ada atau tidaknya sumbat pada erlenmeyer. Pada tabel 3 menunjukkan perbandingan besarnya waktu karakteristik dan konstanta pendinginan air dari erlenmeyer dengan sumbat dan tanpa sumbat yang diperoleh dari tabel 1 dan tabel 2.

Tabel 3. Perbandingan konstanta pendinginan air dari erlenmeyer dengan sumbat dan tanpa sumbat.

\begin{tabular}{ccc}
\hline $\boldsymbol{v}(\mathbf{m} / \mathbf{s})$ & \multicolumn{2}{c}{$\boldsymbol{\alpha}\left(\mathbf{s}^{-1}\right)$} \\
\cline { 2 - 3 } & Dengan sumbat & Tanpa sumbat \\
\hline 0,0 & 0,00032 & 0,00039 \\
0,9 & 0,00044 & 0,00052 \\
1,3 & 0,00048 & 0,00053 \\
2,3 & 0,00066 & 0,00067 \\
2,7 & 0,00068 & 0,00076 \\
\hline
\end{tabular}

Berdasarkan tabel 3 diperoleh informasi bahwa laju pendinginan tanpa menggunakan sumbat lebih cepat dibandingkan dengan menggunakan sumbat baik untuk pendinginan air yang melibatkan angin maupun tanpa angin. Kecepatan pendinginan air juga dipengaruhi oleh 
luas daerah yang mengalami kontak dengan udara. Pada erlenmeyer tanpa sumbat lebih banyak permukaan yang bersentuhan dengan udara sehingga kecepatan pendinginan akan lebih besar dibandingkan dengan erlenmeyer yang disumbat.

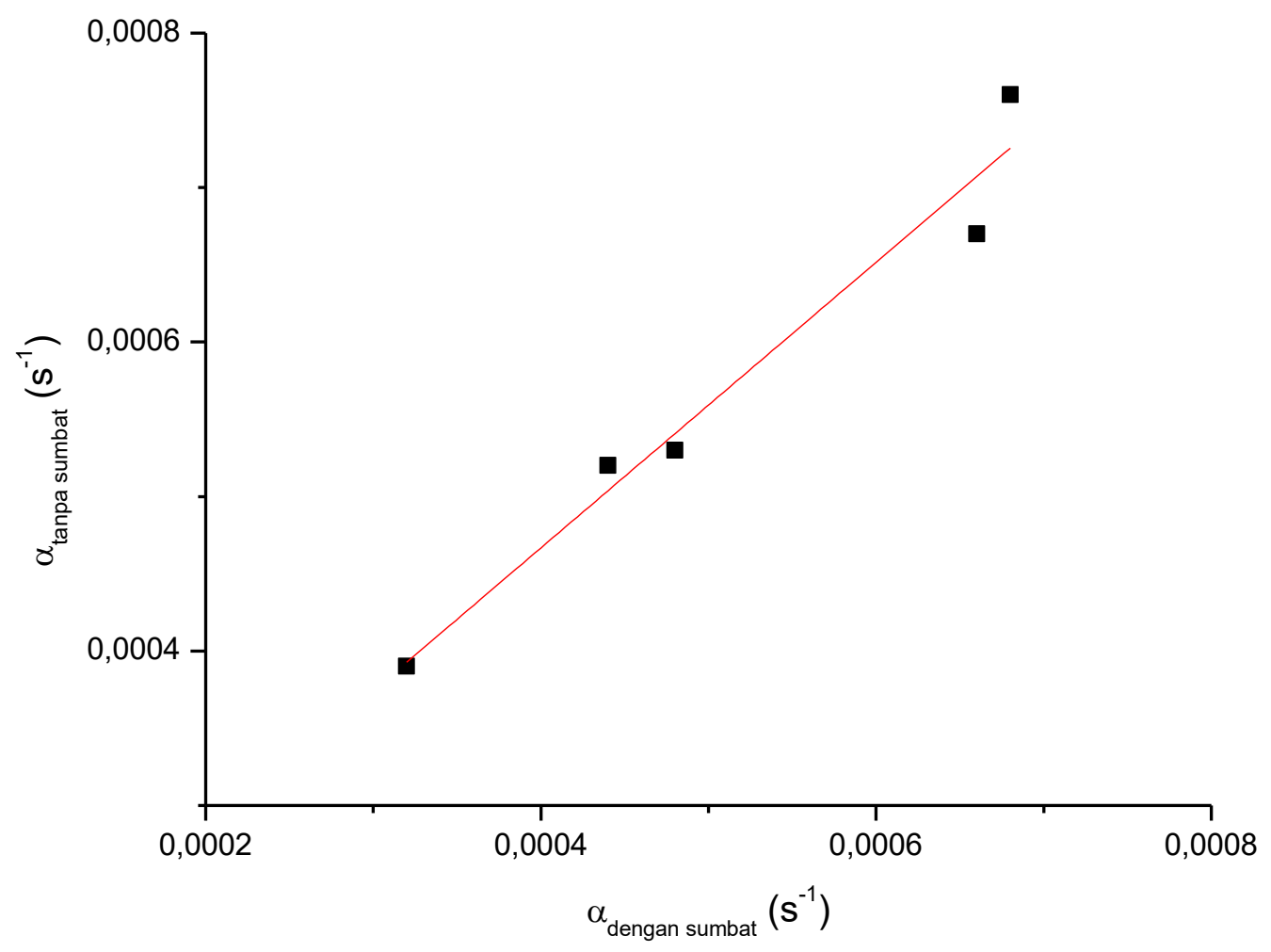

Gambar 5. Analisis regresi linier konstanta pendinginan air dengan dan tanpa sumbat.

Menggunakan analisis regresi linier dari besarnya konstanta pendinginan air untuk erlenmeyer dengan dan tanpa sumbat pada gambar 5, diperoleh persamaan:

$$
y=9,7 \times 10^{-5}+0,92 x
$$

dengan $y$ adalah koefisien pendinginan air dari erlenmeyer tanpa sumbat dan $x$ adalah koefisien pendinginan air dari erlenmeyer dengan sumbat, dan nilai $R^{2}$ sebesar 0,95237 . Nilai intersepsi $9,7 \times 10^{-5} \mathrm{~s}^{-1}$, menunjukkan penambahan besar konstanta pendinginan air ketika terdapat penambahan luas daerah yang mengalami kontak dengan udara karena ketidakadanya sumbat pada erlenmeyer.

\section{Kesimpulan}

Air panas dapat mendingin karena energi panasnya ditransfer ke udara baik dengan cara radiasi, konduksi maupun konveksi. Kecepatan pendinginan air ini diindikasikan dengan besarnya konstanta pendinginan air, untuk kasus tanpa angin pada erlenmeyer dengan sumbat diperoleh $\alpha=3,1 \times 10^{-4} \mathrm{~s}^{-1}$, sedangkan untuk erlenmeyer tanpa sumbat $\alpha=3,8 \times 10^{-4} \mathrm{~s}^{-1}$. Dengan menambahkan angin maka transfer panas secara konveksi akan mengalami paksaan sehingga air akan lebih cepat mendingin. Laju perubahan konstanta pendinginan air terhadap kecepatan angin sebesar $1,4 \times 10^{-4} \mathrm{~m}^{-1}$. Besarnya konstanta pendinginan air juga dipengaruhi 
oleh luas permukaan yang bersentuhan dengan udara, hal ini dibuktikan dengan bertambahnya nilai konstanta pendinginan air rata-rata sebesar $9,7 \times 10^{-5} \mathrm{~s}^{-1}$ ketika sumbat pada erlenmeyer dihilangkan.

\section{Daftar Pustaka}

Giancolli, Douglas C.(2001).FISIKA Jilid 1 Edisi Kelima.Jakarta:Erlangga.

Margenau, Henry., Watson, William W., Montgomery, C.G., (1953), Physics: Principles and Application Second Edition, McGraw Hill.

Ma'sum, Zuhdi., Arsana, Made., Malik, Fathurrahman., Priyono, Wahyudi., Altway, Ali., (2012). Analisis Perpindahan Panas dengan Konveksi Bebas Dan Radiasi pada Penukar Panas Jenis Pipa dan Kawat, Jurnal Teknik Kimia Vol.7, No.1, September 2012

Putra, Nandy., Maulana, Syahrial., Koestoer, R.A., Danardono A.S., (2005), Pengukuran Koefisien Perpindahan Kalor Konveksi Fluida Air Bersuspensi Nano Partikel(Al2O3) pada Fintube Heat Exchanger, Jurnal Teknologi, Edisi No. 2, Tahun XIX, Juni 2005, 116-125 ISSN 0215-1685

Ramadhanti, Putri., Fathurohman, Apit., (2014), Penggunaan Coachlab II+ dalam Menentukan Koefisien Konveksi, diakses pada tanggal 4 april 2016 dari http://ejournal.unisri.ac.id/index.php/jipf/view/1806/751.

Tipler, P.A., (1998), Fisika untuk Sains dan Teknik Jilid 1 (Terjemahan), Jakarta : Erlangga 